\title{
Observation of Precipitation and Drop-Size Distribution Associated with a Typhoon using VHF Radar
}

\author{
V.K. Anandan ${ }^{*}$, , C.J. Pan $^{2}$, K. Krishna Reddy ${ }^{3}$, T. Narayana Rao ${ }^{4}$ and S.Vijaya Bhaskara Rao ${ }^{5}$ \\ ${ }^{I}$ ISTRAC, Indian Space Research Organisation, Peenya, Bangalore-58, India \\ ${ }^{2}$ Institute of Space Science, National Central University, Chung-Li, Taiwan \\ ${ }^{3}$ YogiVemmana University, Kadappa, AP, India \\ ${ }^{4}$ National Atmospheric Research Laboratory, Gadanki, India \\ ${ }^{5}$ Sri Venkateswara University, Tirupati- 517 502, India
}

\begin{abstract}
This paper describes some of the microphysical and kinematic properties of precipitating systems associated with a typhoon using Chug-Li VHF radar. In order to gain a better understanding of these mechanisms and the vertical structure of the precipitation associated with a typhoon at different stages of development, an analysis has been carried out of the radar back-scattered signal in order to obtain the power, velocity and velocity width of the Doppler spectrum of clear air and hydrometeors. The vertical profiles of raindrop size distribution (DSD) parameters are estimated through model-based regression analysis. The study reveals that during a typhoon, different convective and stratiform types of precipitation occur at different times with varying intensities. This study also reports on some of the characteristic features of the convective systems observed during the typhoon.
\end{abstract}

Keywords: Precipitation, mesoscale meteorology, convective processes, VHF radar, drop size distribution.

\section{INTRODUCTION}

High power VHF radar has a unique capability of observing back ground air motion, making use of scattering of radio waves from irregularities in the atmospheric index of refraction due to turbulence, with fine time and height resolutions. The ability of these radars in providing $3 \mathrm{D}$ wind field continuously in all weather conditions make them a valuable addition to the existing network of meteorological soundings. Utilization of these radars for meteorological applications has been reviewed by Balsley and Gage [1] and Larsen and Röttger [2]. Though, VHF radars are mainly sensitive to refractive index fluctuations, they can also sense hydrometeors when the precipitation is moderate to reasonably heavy in the scattering volume. To find out, quantitatively, what kind of precipitation (in terms of radar reflectivity factor, $Z$ ) would be required to get the precipitation echo with a strength comparable to that of clear air echo, one should equate the equations of volume reflectivity for Rayleigh scattering and Braggs scattering [3] as,

$$
d B Z=10\left(\log C_{n}^{2}+\log \lambda^{2 / 3}+15.13\right)
$$

where, $C_{n}^{2}$ is the refractivity turbulence structure constant $\left(\mathrm{m}^{-2 / 3}\right), \lambda$ the radar wavelength $(\mathrm{m})$ and $d B Z=10(\log Z)$. Given a $C_{n}{ }^{2}=10^{-15}$ (typical values in the lower troposphere), one would require the precipitation strength to be of the

\footnotetext{
*Address correspondence to this author at the RDA, ISTRAC/ISRO, Indian Space Research Organisation, A1-6, Peenya, Bangalore-560058, India;

Tel: 91802809 4483; E-mail: anandanvk@hotmail.com
}

order of $30 \mathrm{dBZ}$, in order to get considerable precipitation echo.

In the presence of moderate to heavy precipitation, Doppler spectra at VHF often contain two peaks: one due to hydrometeors and the other due to clear-air back scattered echoes. The peak at larger Doppler velocity (taking sign into consideration) comes from the refractive index fluctuation, where as the second one is due to precipitation. Various techniques for separating these echoes are reported. They generally follow two approaches: 1 . fitting Gaussian function to the turbulence (clear air) echo [4-6], and 2. separation of these two echoes by considering the minimum power point between these two peaks represents the boundary [7]. Recently, attempts have also been made to separate these echoes objectively [8] from VHF radar spectra. With VHF radars, it is, thus, possible to measure mean vertical air motion (up- and down-drafts) and also fall speed spectrum of precipitation particles.

Studies on precipitating systems with VHF wind profilers have been made by many researchers in the past [4-7, 9-16]. Some of these studies focused on characterizing different types of precipitating systems, the radar bright band and turbulence and precipitation echo structures, while other studies focused on retrieving the rain drop size distributions using a single frequency technique. However, there exists only few research studies related to typhoons using VHF radars in the literature [17-19]. These studies tried to reveal the structure of mesoscale wind circulations during the passage of typhoons and to study the disturbances (or waves) they generate during their passage over the radar site. 
On the other hand, observations of rain drop-size distribution (DSD) as a function of precipitation intensity and height have been made widely all over the world and also in various types of precipitating systems. Such an information is extremely useful in studying the microphysics of rain systems, cloud modeling, microwave attenuation etc. The vertical distribution of rain DSD provides clues to the evolution of precipitating systems, like growth and decay processes. In his seminal work, Wakasugi et al. $[15,16]$ developed a model to retrieve raindrop size distribution using the precipitation portion of the VHF radar spectra, after correcting it for vertical air motion. Major drawbacks of this model are: 1. the assumption of specific shape to raindrop size distribution (exponential) [20], and 2. requirement of initial guess values. This method was later automated by Sato et al. [14], who used a computer algorithm to fit the observed spectra with theoretical spectra with the help of non linear least square fitting analysis. Subsequent studies used the same technique but with different assumed shapes to the precipitation echo [4, 21]. Another approach to retrieve rain DSD is through direct deconvolution [6]. This approach doesn't assume any apriori shape to the precipitation echo, unlike fitting techniques. In the present study, modified version of Sato et al. [14] has been used for retrieving rain DSD [21].
The Stratosphere-Troposphere (ST) radar at Chung-Li $\left(24^{\circ} 58^{\prime} \mathrm{N}, 121^{\circ} 11^{\prime} \mathrm{E}\right)$, Taiwan is an ideal location to study typhoons in their developing stage since it is in the middle of a typical course of system. One such event, when typhoon Lekima passed over the radar site, was considered for the present study. The observations made in this case study were unique, since the passage of the typhoon centre is close to the radar site (just $300 \mathrm{~km}$ away) unlike in similar studies in which the typhoon was far away from the radar site. The main aim of this report is to study characteristics of the turbulence and precipitation echoes in different precipitating systems and to retrieve and study rain DSD associated with those systems during the passage of a typhoon. Section 2 describes the observations carried out with the radar during the passage of typhoon. The characteristics of turbulence and precipitation echoes are compared and contrasted in different precipitating systems in section 3 . The rain DSD retrieval technique is elaborated in section 4 . Results pertaining to rain DSD and comparisons with rain gauge measurements are also discussed in section 4 . The results are summarized and conclusions are drawn in section 5 .

\section{RADAR OBSERVATION}

Typhoon Lekima (No.0119, 2001), was developed near southeast of Taiwan $\left(19^{\circ} \mathrm{N}, 124^{\circ} \mathrm{E}\right)$, crossed south of Taiwan

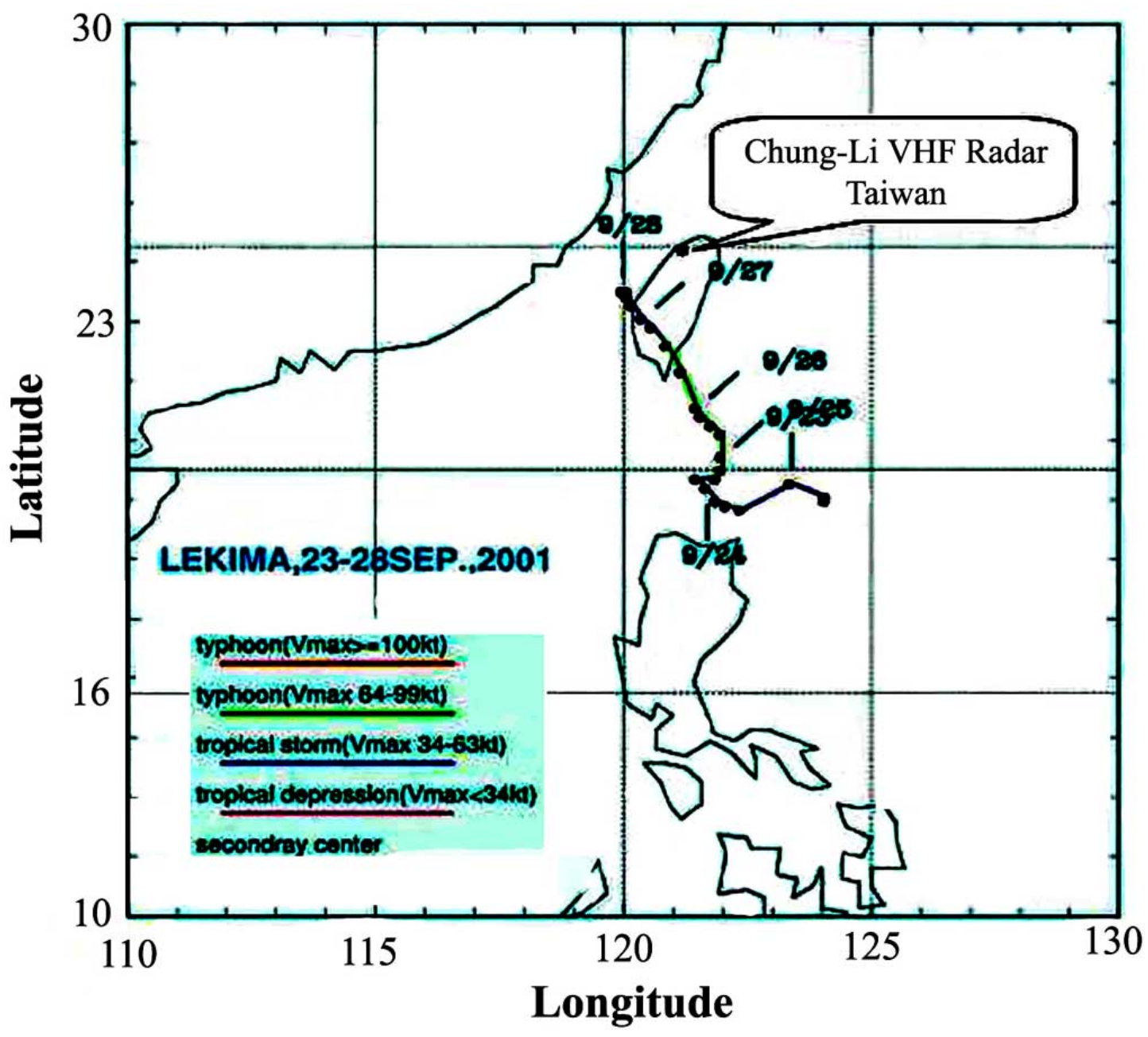

Fig. (1). Path of typhoon Lekima from 23 to 28 September 2001. 

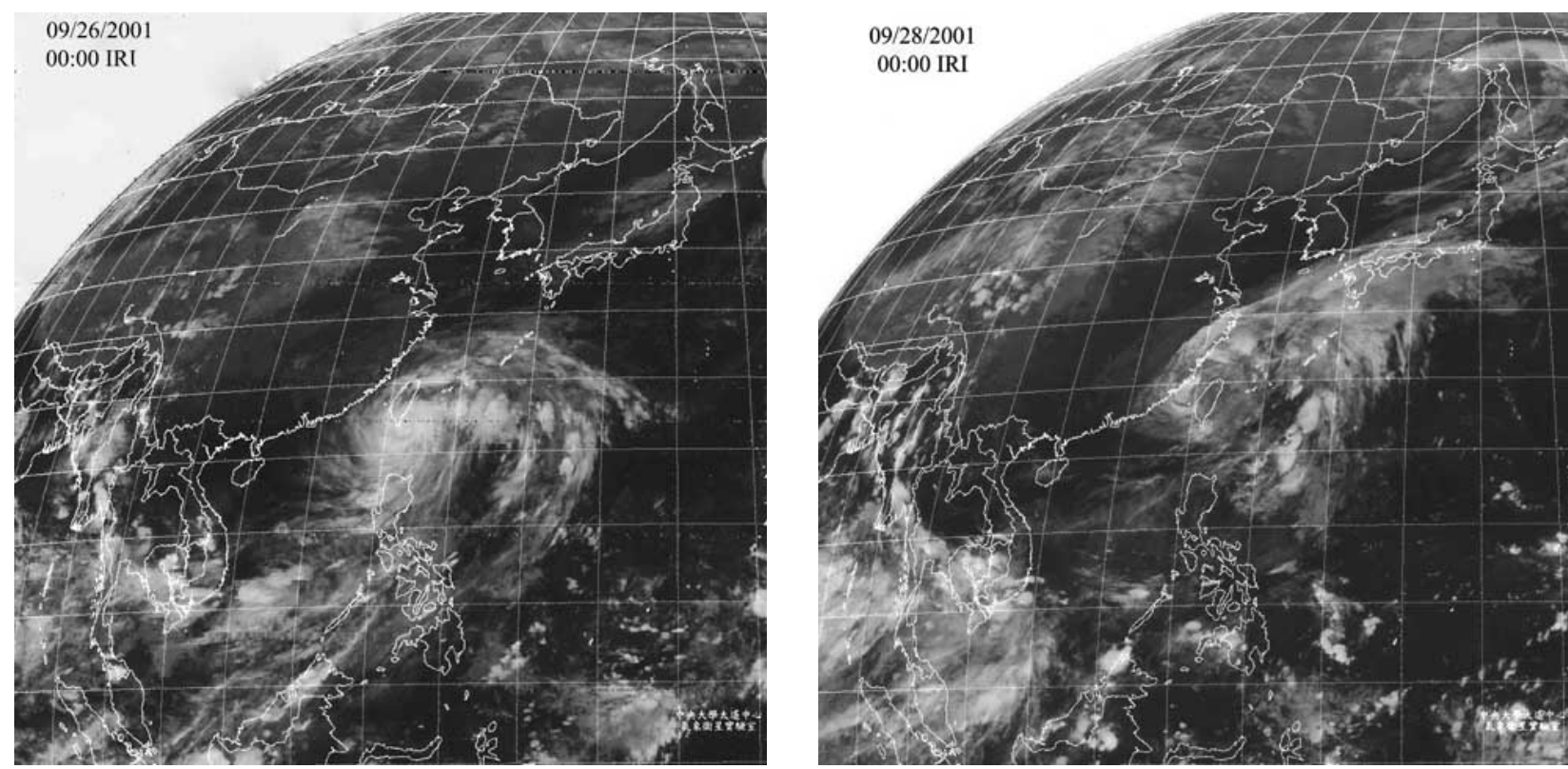

Fig. (2). Satellite image of cloud systems associated with typhoon Lekima on (a) 26 September 2001 and (b) 28 September 2001.

on 26 September 2001 as shown in Fig. (1). The core of the typhoon was around $300 \mathrm{~km}$ away from the radar site. However, the cloud band covered the entire land from $25^{\text {th }}$ September onwards which was clearly evident from the satellite pictures of cloud system associated with the typhoon (Fig. 2). During the passage of typhoon, the radar was operated continuously for about 120 hours (between 25 and 30 September 2001). Main specifications of the radar observations are $2 \mu$ s pulse width (corresponding to $300 \mathrm{~m}$ range resolution), $400 \mu \mathrm{s}$ inter pulse period, 256 coherent integrations, and 256 FFT points. Temporal resolution for the data collected during the above period is $30 \mathrm{sec}$ Complete system description of the radar is given in [22].

\section{CHARACTERISTICS OF MOMENTS FOR TURBULENCE AND PRECIPITATION ECHOES}

For the present study, VHF radar data collected on 26, 27, and 28 September 2001 have been used as on these days, the Doppler spectra show a clear bimodal signature in most of the observations. Precipitation was either intermittent or not strong enough to be detected by VHF radar on other days. Fig. (3a) shows the typical power spectra with clear air
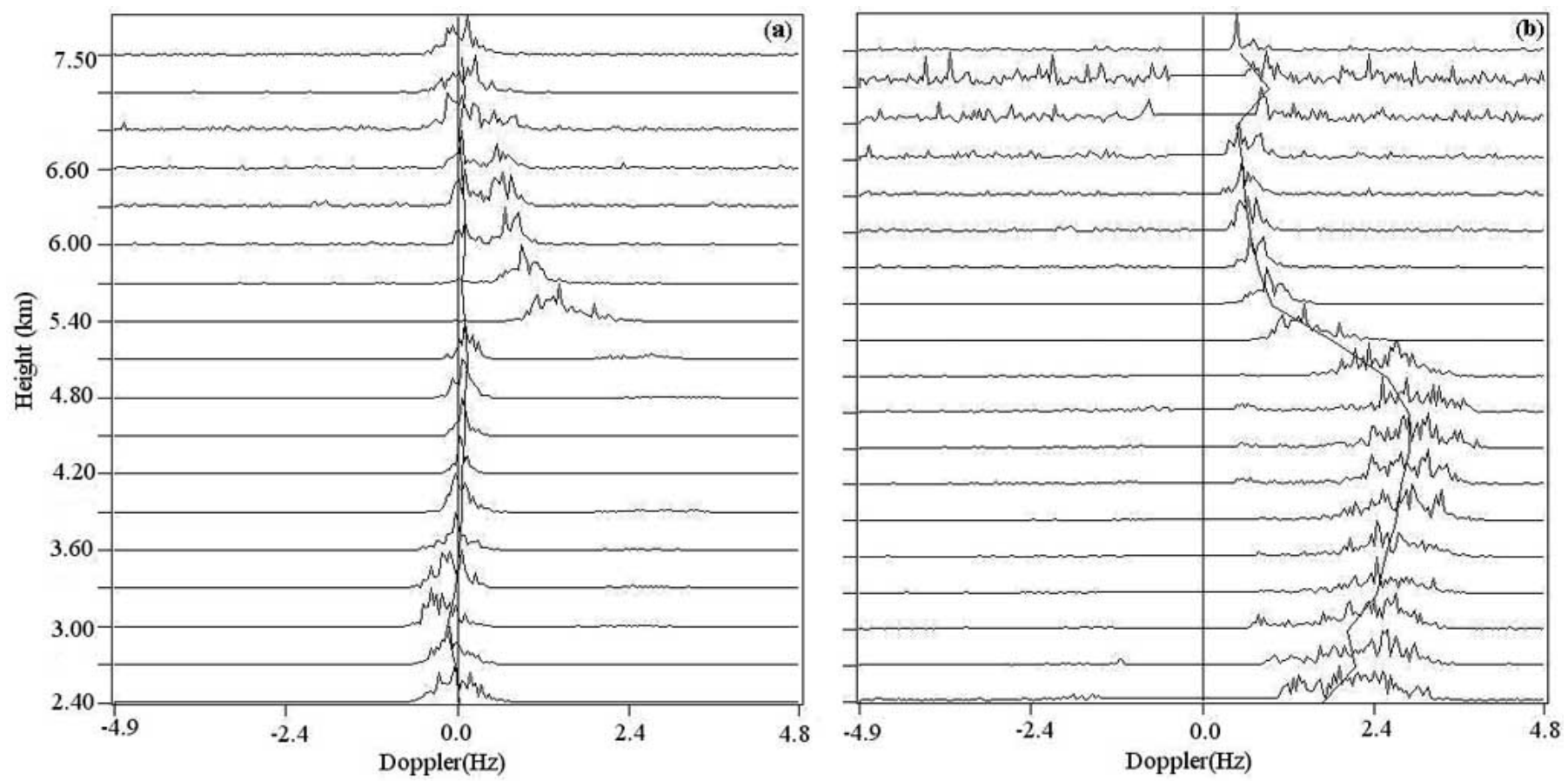

Fig. (3). Range normalized profile of Doppler power spectrum (a) clear air + precipitation (b) precipitation alone. Solid line over the spectra shows the estimated mean Doppler shift. 
and precipitation echoes. Since the precipitation echo power is weaker than clear air echo power at all heights (except in the vicinity of the $0^{\circ} \mathrm{C}$ isotherm level), they are not visible in the range of normalized plot. To obtain stable and smoother (noise free) spectra, several spectra were incoherently integrated with varying lengths of integration. In normal conditions (in other words, during stratiform precipitation), when the vertical velocity is $<1 \mathrm{~ms}^{-1}$, the integration was done for 3 minutes. If the velocity exceeds 1 $\mathrm{ms}^{-1}$, then the integration was done only for 1 minute. The clear air and precipitation echoes are identified in the spectral domain, following [6] and [7]. The minimum spectral point between the clear air and precipitation peaks is identified and is considered as the boundary between the echoes. A tail is added to both echoes [6] from the identified boundary point to the noise floor. Fig. (3b) is the precipitation spectra alone after separating it from clear air echoes. Mean noise level is estimated using the method proposed by [23]. The three lower order moments are then estimated, using the standard formulae [24], for both clear air echo and precipitation echo. The solid line drawn over the spectra (Fig. 3a, b) show the mean Doppler frequency estimated by the above method.

Figs. $(4,5)$ show the vertical profiles of profiler moments on 26, 27 and 28 September 2001, for clear air and precipitation echoes respectively. During these days, the echoes are separated whenever the spectra show a clear bimodal structure. As also noticed by [7], all clear echo power profiles show a drastic reduction in power around the $0^{\circ} \mathrm{C}$ isotherm level. The temperature information is obtained from a radiosonde launched from a nearby station, Hualein. The temporal variation of the $0^{\circ} \mathrm{C}$ isotherm level is shown in Fig. (6); on average, this level is around $5.4 \mathrm{~km}$ on above days. The backscattered power reduction with respect to the power at 4.8/5.1 km is ranging from 7-12 $\mathrm{dB}$, in many of the profiles. Rao et al. [7] and Chu et al. [9] argued that the reduction in power may be associated with the turbulent mixing of cloud warm and humid air with the ambient dry and cooler air. The former has noticed the power reduction during weak convection (i.e., when the vertical air motion is greater than $1.2 \mathrm{~ms}^{-1}$ ), whereas the later observed the reduction at the height of the radar bright band, which is similar to the observations reported here.

The vertical air motion profiles (Fig. 4b, e, h) are generally within $\pm 0.5 \mathrm{~ms}^{-1}$, except those observed at 10 and $14 \mathrm{LT}$ on $27 \mathrm{Sep}$. and $15 \mathrm{LT}$ on $28 \mathrm{Sep}$. It is now well accepted that the vertical air motion is generally weak in stratiform rain, while it exceeds $1 \mathrm{~ms}^{-1}$ in convection [25, 26]. According to the above definition, the periods, when the vertical air motion exceeds $\pm 1 \mathrm{~ms}^{-1}$, can be considered as associated with convection. But, the convection observed in our study seems to be weak compared to the events reported [7]. During convection, the clear air echo power profiles show a complex structure with strong backscatter even from higher altitudes. Also, the reduction of clear air echo power during convection period is lesser than that observed at other times. During this period, relatively strong up- and downdrafts are seen with large spectral widths indicating the existence of severe turbulence. Spectral widths in excess of $2.5 \mathrm{~ms}^{-1}$ are observed during convection (Fig. $\left.4 \mathbf{c}, \mathbf{f}, \mathbf{i}\right)$. On the other hand, the spectral width profiles in stratiform rain are found to be relatively weak $\left(<2 \mathrm{~ms}^{-1}\right)$.
All backscattered power profiles for precipitation echo (Fig. 5a, d, g), except those observed during convection, show a strong enhancement of echo power, of the order of 10-12 dB, centered at around $5.4 \mathrm{~km}$. This enhancement of power is generally termed as the radar bright band and is a typical signature of stratiform rain. The bright band forms because of the aggregation of ice flakes and melting of large aggregates around the $0^{\circ} \mathrm{C}$ isotherm level. Due to continuous aggregation, the fall velocity profiles (corrected for vertical air motion) also show a steep gradient around 5.4 $\mathrm{km}$. The reduction in backscattered power below the bright band peak could be attributed to the reduction of hydrometeor concentration caused by increase in fall velocity of hydrometeors. The updrafts and downdrafts and associated turbulence disrupt radar bright band. Chu and Song [27] noticed the disruption of bright band, whenever the clear air velocity exceeds $1.2 \mathrm{~ms}^{-1}$. The spectral widths for precipitation echo are, in general, found to be within the range of 1-4 $\mathrm{ms}^{-1}$ with larger values in convection.

Comparison of clear air and precipitation echo power indicate the dominance of clear air echo power over precipitation echo power both above and below the radar bright band, while the precipitation echo power is more in the radar bright band. These results are largely consistent with earlier studies reported by using the VHF radar [6, 7]. Further, one can see within the observation window the reflectivity almost remains constant between 4.5 and $3.0 \mathrm{~km}$ for the stratiform type of events and below it decreases. This may be due to breaking of drop giving rise to higher number of smaller drops and evaporation at lower heights, hence a decrease in radar reflectivity observed. The horizontal and vertical velocity of background wind may also affect the reflectivity profile of the precipitation echoes. Unlike in microwave radar, big radars having large aperture will have a reduced gain in the near field zone, which is related to antenna beam formation. This may be another reason for reducing the reflectivity below $3 \mathrm{~km}$ height. In general, the spectral width of precipitation echo is larger than that of clear air echo. The broadening of precipitation echo contains the information of rain DSD. However, it has to be corrected for broadening due to turbulence and non-turbulence sources (like beam broadening).

\section{RETRIEVAL OF RAIN DSD AND COMPARISON WITH RAIN GAUGE PRODUCTS}

Since radar reflectivity is proportional to sixth power of its drop diameter, the contribution from smaller-sized particles becomes weak. At the smallest end of the size distribution where the drop fall velocity becomes much smaller than wind velocity fluctuations due to atmospheric turbulence, it is difficult get rain DSD. Due to this reason, the scanty and weak precipitation was not possible to observe with the VHF radar. The analysis carried out on only those spectral data, which show clear bimodal characteristics.

The observed Doppler spectrum $\mathrm{S}(\mathrm{v})$ due to raindrop and atmospheric turbulence is expressed as

$\mathrm{S}(\mathrm{v})=\mathrm{S}_{\mathrm{t}}(\mathrm{v})+\mathrm{S}_{\mathrm{p}}(\mathrm{v}) * \mathrm{~S}_{\mathrm{o}}(\mathrm{v})+\mathrm{P}_{\mathrm{n}}$

where, $\mathrm{S}_{\mathrm{t}}(\mathrm{v})$ is the turbulence spectrum and can be written as for the assumed Gaussian distribution [14, 28]. 

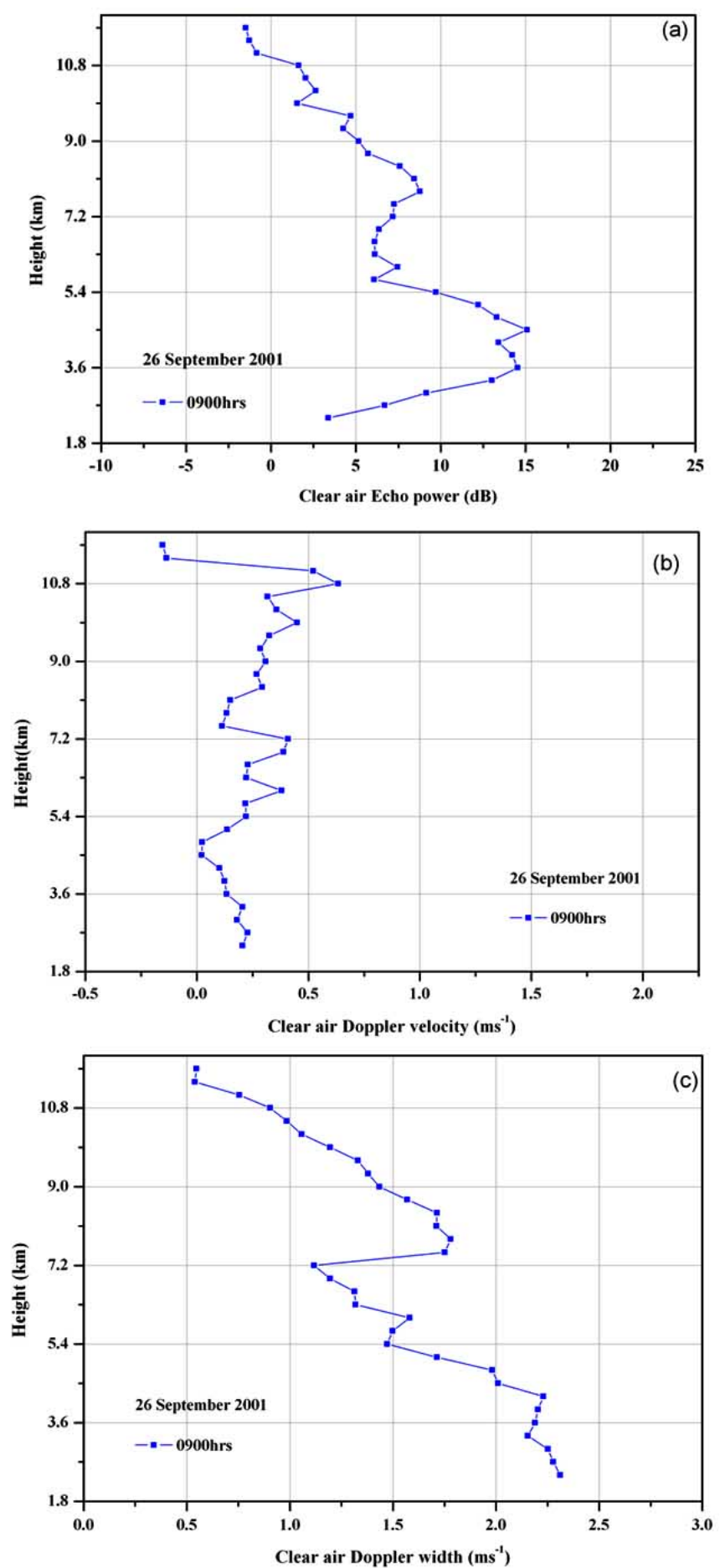

(Fig. 4) contd.....
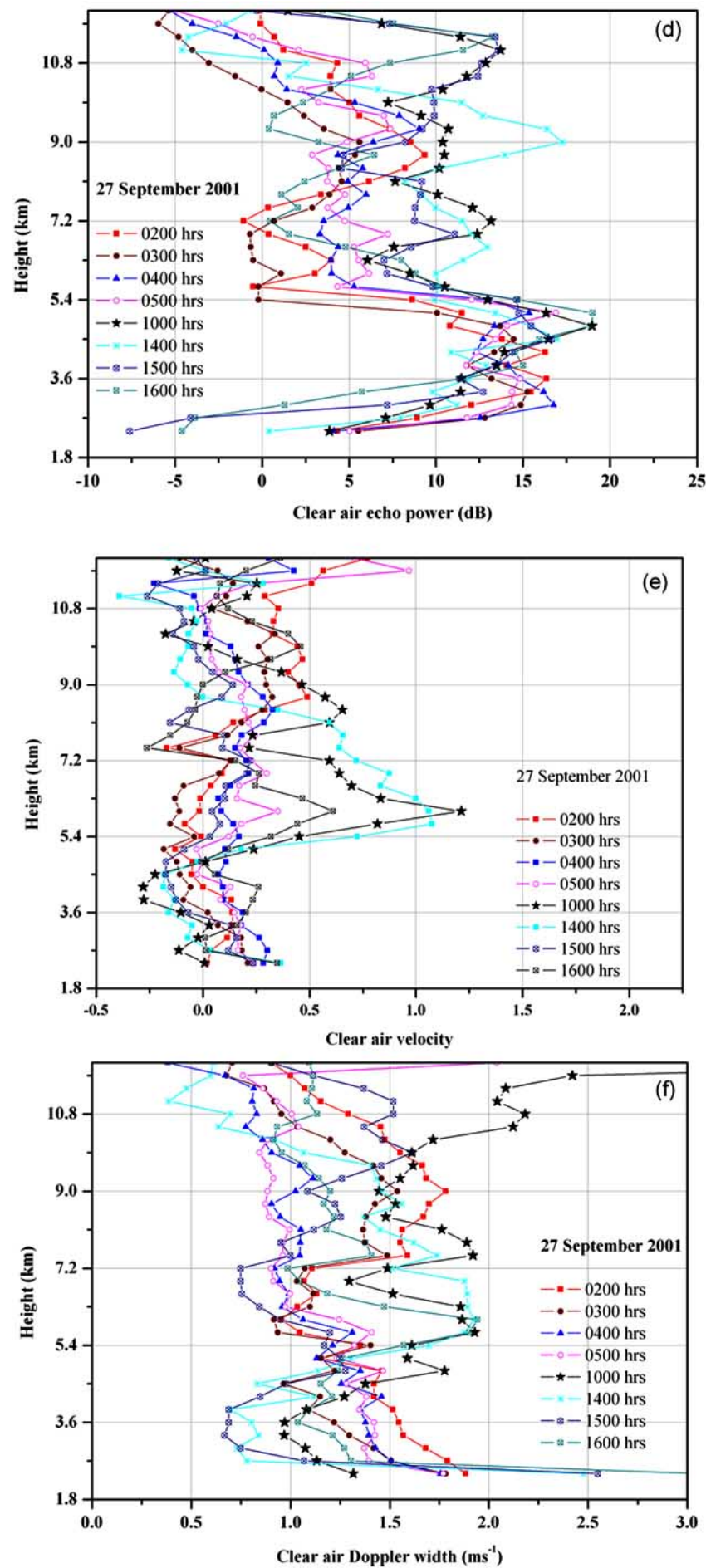
(Fig. 4) contd.....
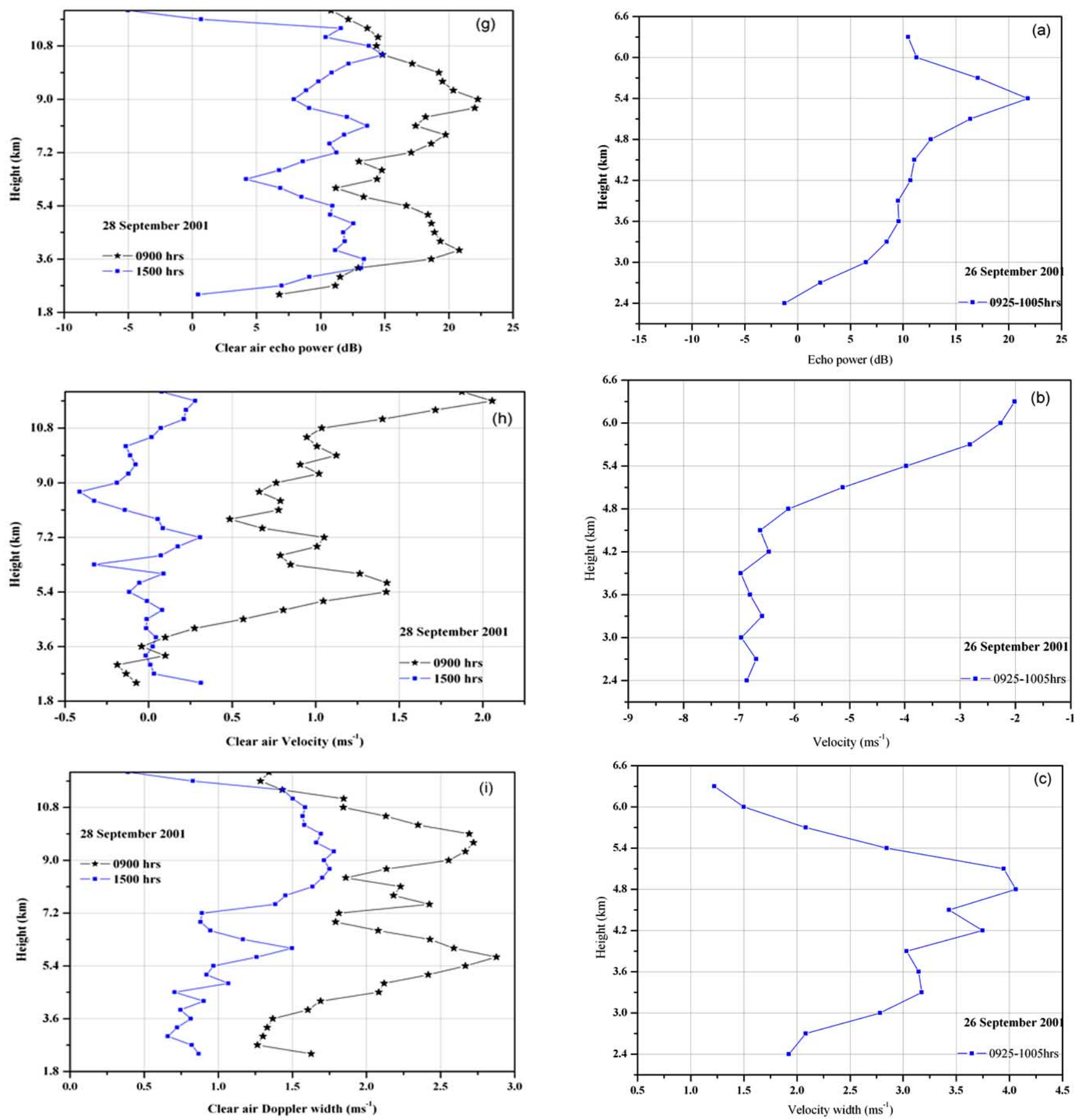

Fig. (4). Power, mean Doppler velocity and Doppler width of clear echoes observed on 26, 27 and 28 September 2001 by Chung-Li VHF radar. 
(Fig. 5) contd.....
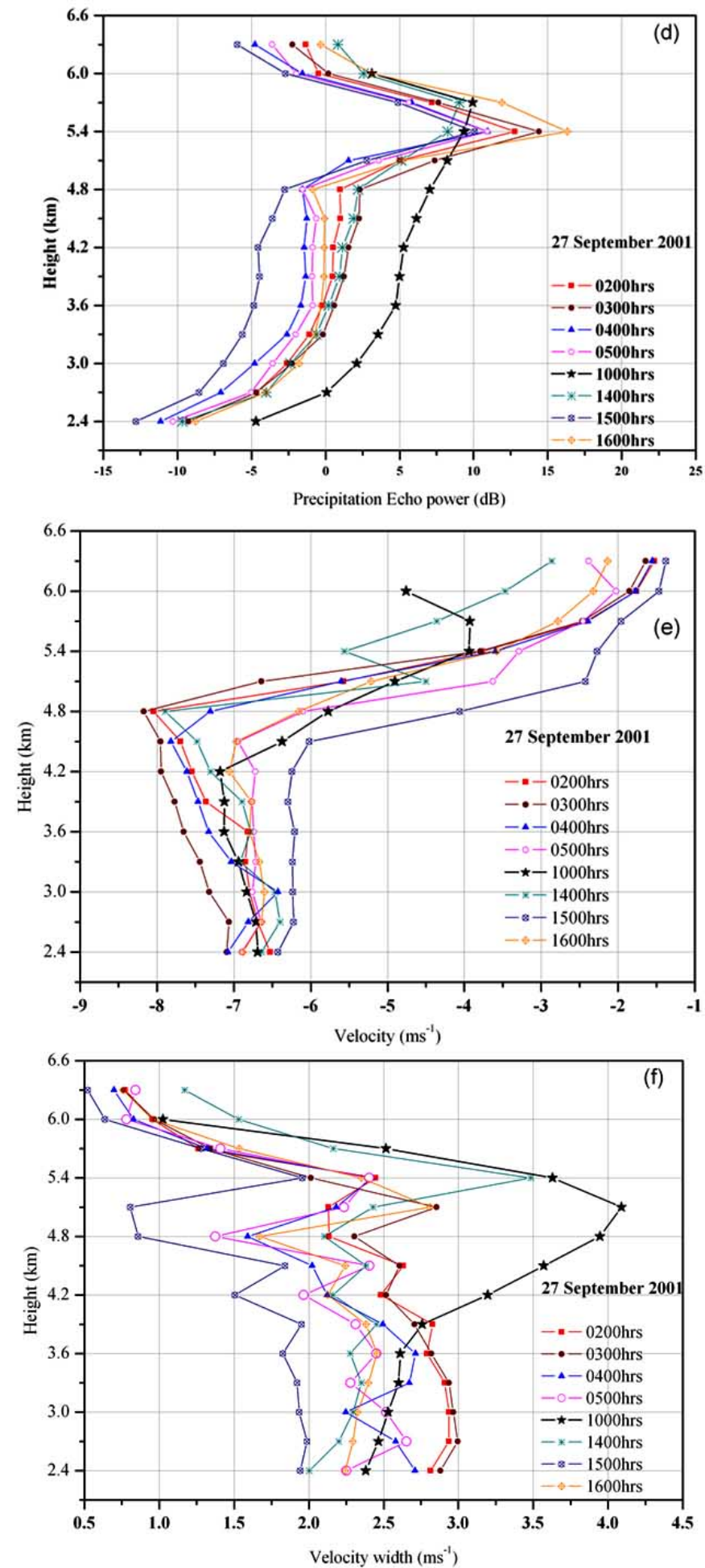

(Fig. 5) contd....
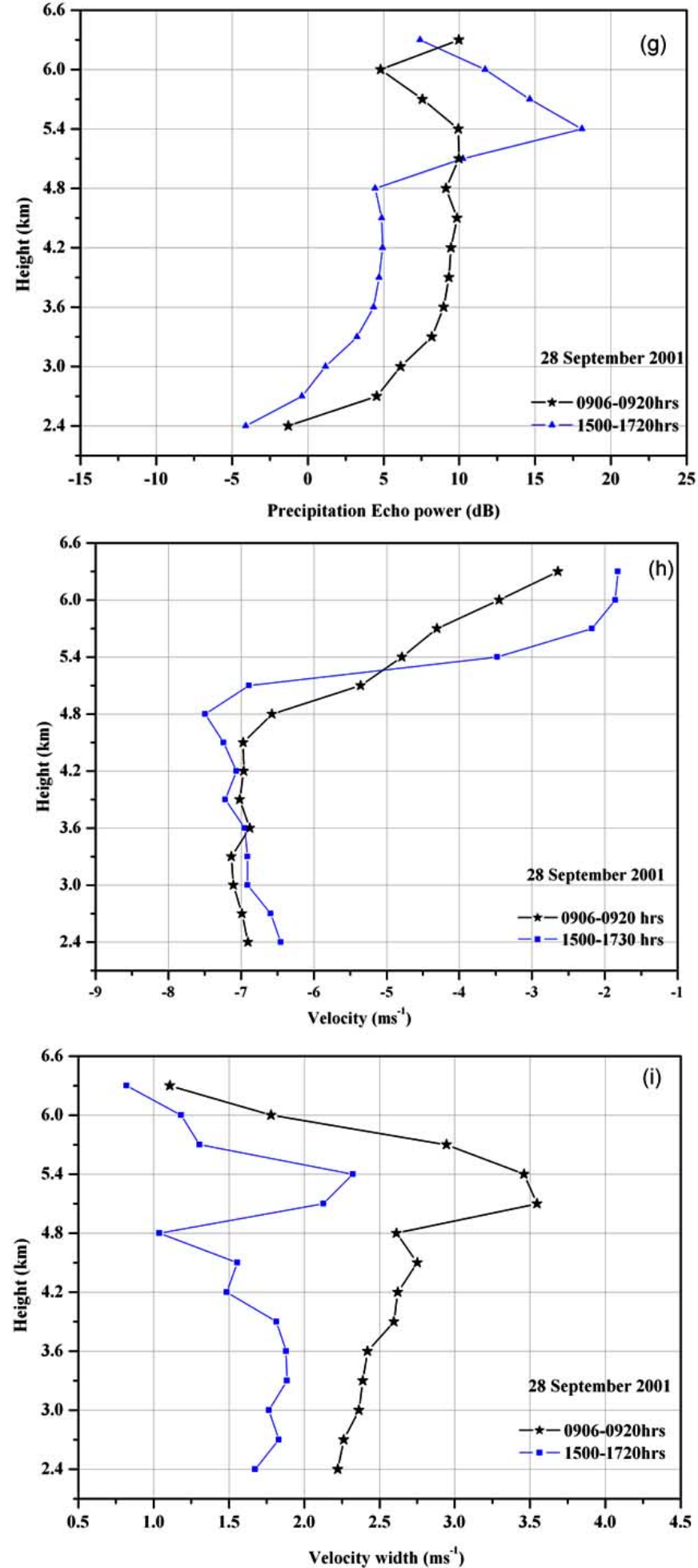

Fig. (5). Same as Fig. (4), except for precipitation echoes. 


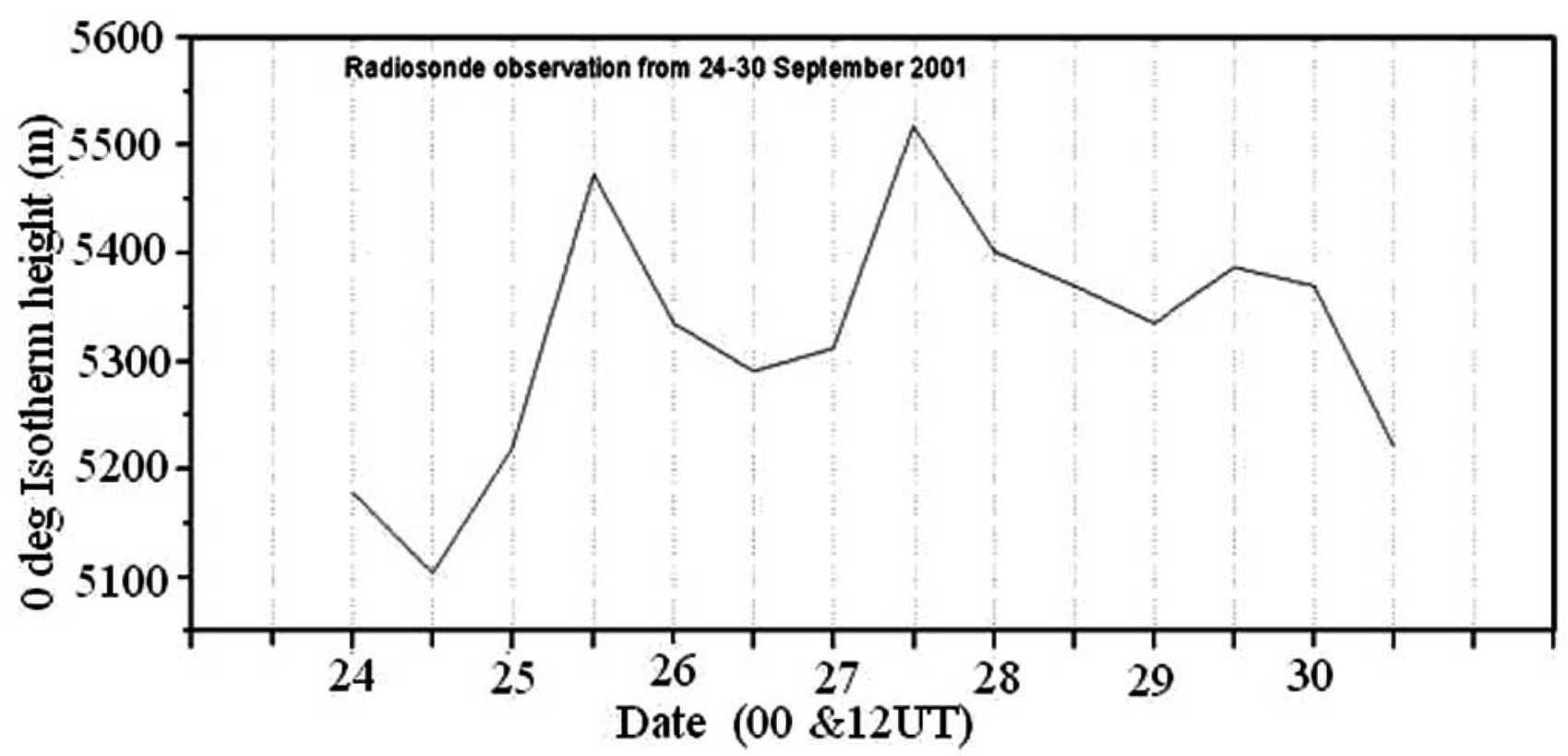

Fig. (6). Temporal variation of the $0^{0} \mathrm{C}$ isotherm level during the observational period $(24-30$ September 2001). Temperature information is obtained from radiosonde measurements.

$S_{t}(v)=P_{0} \exp \left[\frac{-(v-w)^{2}}{2 \sigma^{2}}\right]$

where $\mathrm{P}_{0}$ is the spectrum power, $\mathrm{w}$ is the mean radial wind velocity and $\sigma$ is the spectral broadening.

$\mathrm{S}_{\mathrm{p}}(\mathrm{v})$, Doppler velocity spectrum, due to precipitation, by a vertically pointing radar beam in the absence of atmospheric turbulence and wind, can be expressed in terms of diameter of raindrops (D) as

$\mathrm{S}_{\mathrm{p}}(\mathrm{v})=\mathrm{C} \cdot \mathrm{N}(\mathrm{D}) \mathrm{D}^{6}\left|\frac{d[v(D)]}{d D}\right|^{-1}$

where, $N(D) d D$ is the number of particles with diameters between $\mathrm{D}$ and $\mathrm{D}+\mathrm{dD}$, and for generalized gamma distribution it is defined as [29].

$\mathrm{N}(\mathrm{D})=\mathrm{N}_{0} \mathrm{D}^{\mu} \exp (-\Lambda \mathrm{D})$

Parameter $\mu$ may have values from -3 to 8 and $\mathrm{N}_{0}, \Lambda$ are functions of rain rate $[30,31]$.

$v(\mathrm{D})$ is the drop fall velocity, $\mathrm{C}$ is a constant. The terminal velocity is related to the drop diameter through the equation [32] as

$v(D)=-[9.65-10.3 \exp (-0.6 \mathrm{D})]\left(\rho_{0} / \rho\right)^{0.4}$

where, $v$ is in $\mathrm{ms}^{-1}, \mathrm{D}$ in $\mathrm{mm}$, and $\rho_{0}$ and $\rho$ are air densities at ground level and at the level of observation, respectively. Positive velocities indicate upward motion. For standard atmosphere, air density can be modeled as [19]

$10 \log _{10}\left(\rho_{\text {air }}\right)=-0.477 \mathrm{~h}+0.988$

where $\mathrm{h}$ represents the height above sea level in $\mathrm{km}$.

$\mathrm{S}_{\mathrm{o}}(\mathrm{v})$ is a normalized form of $\mathrm{S}_{\mathrm{t}}(\mathrm{v})$,

$S_{0}(v)=\frac{1}{(2 \pi)^{1 / 2} \sigma} \exp \left[\frac{-(v-w)^{2}}{2 \sigma^{2}}\right]$
$\mathrm{P}_{\mathrm{n}}$ is the noise level on the spectra and the asterisk denotes the convolution operation.

Due to finite data length and Fast Fourier Transform (FFT) analyses, the Doppler spectra are distorted by the window function, $\mathrm{W}(\mathrm{v})$, as expressed below

$\mathrm{S}^{\prime}(\mathrm{v})=\mathrm{S}(\mathrm{v}) * \mathrm{~W}(\mathrm{v})$

where $\mathrm{W}(\mathrm{v})$ is an inverse Fourier transform of a triangular auto correlation function of the rectangular window. Theoretically estimated S'(v) contain information about DSD of precipitation and atmospheric turbulence. In order to deduce information from the observed spectra a spectral fitting method was devised by $[15,16]$, which is to find a parameter set that minimizes the difference ' $\varepsilon$ ',

$$
\varepsilon=\sum_{i=1}^{N_{F F T}}\left[S_{o b s}\left(v_{i}\right)-S^{\prime}\left(v_{i}\right)\right]^{2}
$$

where $v_{\mathrm{i}}$ 's are discrete velocity points corresponding to $\mathrm{i}^{\text {th }}$ discrete frequency of FFT and $\mathrm{N}_{\mathrm{FFT}}$ is the number of fitted points in the periodogram.

The parameters to be obtained by the fitting are $\mathrm{P}_{0}, \mathrm{w}, \sigma$, $\mathrm{N}_{0}, \Lambda, \mathrm{V}_{\max }$ and $\mathrm{P}_{\mathrm{n}}$. The method works very well when a good initial guess for the parameters is provided. However, manual feeding of initial guess values of each spectrum is impractical, particularly dealing with a large volume of data. Sato et al. [14] devised an automated approach to obtain the initial guess parameters for the algorithm. The initial values for $\mathrm{P}_{0}, \mathrm{w}$, and $\sigma$ are estimated from the observed turbulent (clear air) Doppler spectra by taking the lower three order moments and the mean noise level, $\mathrm{P}_{\mathrm{n}}$. It is known that the raindrops larger than about $6 \mathrm{~ms}^{-1}$ will break into smaller drops either by collisional or spontaneous breakup mechanisms. Using (5) the maximum fall velocity attainable by a biggest drop is around $9.6 \mathrm{~ms}^{-1}$, which is used as $\mathrm{V}_{\max }$ in the fitting. 
To estimate DSD parameters and to perform the nonlinear least square fitting, a different parameterization is used [21], which treats moments of DSD as DSD parameters. The $\mathrm{x}^{\text {th }}$ moment, $\mathrm{M}_{\mathrm{x}}$ and $\mathrm{y}^{\text {th }}$ moment, $\mathrm{M}_{\mathrm{y}}$ are expressed as

$\mathrm{M}_{\mathrm{x}}=\mathrm{N}_{0} \Gamma(\mu+\mathrm{x}+1) / \Lambda^{(\mu+\mathrm{x}+1)}$

$\mathrm{M}_{\mathrm{y}}=\mathrm{N}_{0} \Gamma(\mu+\mathrm{y}+1) / \Lambda^{(\mu+\mathrm{y}+1)}$

By fixing $\mu$ and using $\mathrm{M}_{\mathrm{x}}$ and $\mathrm{M}_{\mathrm{y}}$, DSD parameters $\left(\mathrm{N}_{0}\right.$, $\Lambda)$ can be estimated.

Letm $_{\mathrm{x}}=\mathrm{M}_{\mathrm{x}} / \Gamma(\mu+\mathrm{x}+1)$ and $\mathrm{m}_{\mathrm{y}}=\mathrm{M}_{\mathrm{y}} / \Gamma(\mu+\mathrm{y}+1)$

$\mathrm{N}(\mathrm{D})=\mathrm{M}_{\mathrm{y}} \Lambda^{(\mu+\mathrm{y}+1)} \mathrm{D}^{\mu} \exp (-\Lambda \mathrm{D})$ and $\Lambda=\left(\mathrm{m}_{\mathrm{x} /} \mathrm{m}_{\mathrm{y}}\right)^{1 /(\mathrm{y}-\mathrm{x})}$

Using equations (10.a) and (10.b) and the observed spectrum, an initial value for $\left(\mathrm{N}_{0}, \Lambda\right)$ can be obtained. Once the fitting is done the estimated parameters can be made use to derive all other moments using the equation (10). Fig. (7a, b) show height normalized profile of sample power spectra plots with fitting during two different precipitation events. The fluctuating line is the observed power spectra and

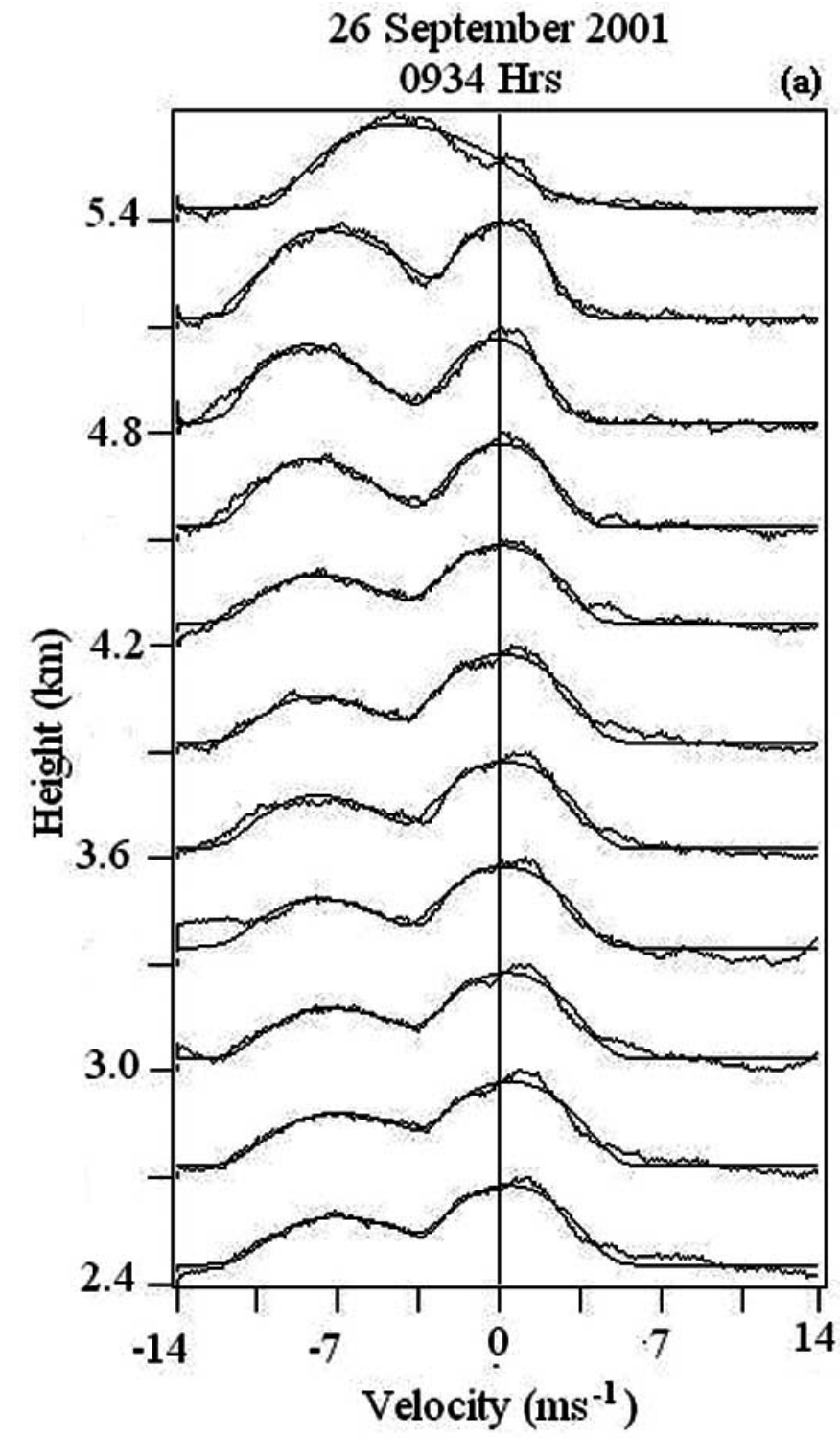

smooth-solid line is the spectra deduced using model. Note that the plots were drawn in logarithmic scale.

Since radar is not calibrated to its absolute power, there is no direct way to get absolute value of precipitation parameters. Here we report only values, which are in arbitrary units. The estimated echo power, mean velocity, velocity width of clear air and noise power were fed along with logarithmic Power Spectral Density (PSD) to the algorithm to estimate the precipitation parameters by using non-linear least square fitting technique. Fitting fails when clear air and precipitation echoes are very close to each other or indistinguishable. So the observations were reported only from $2.4-5.1 \mathrm{~km}$ height region.

Fig. (8a-c) show contours of radar reflectivity, $\mathrm{Z}_{\mathrm{e}},(\mathrm{dBZ})$, rain rate, and drop concentration, respectively, estimated from the measurements made on 27 September 2001 during 03-04 LT. During this time precipitation is classified as stratiform and the maximum intensity of rain observed is 1.7 $\mathrm{mm} / \mathrm{hr}$ and maximum drop concentration is 3156 . One can

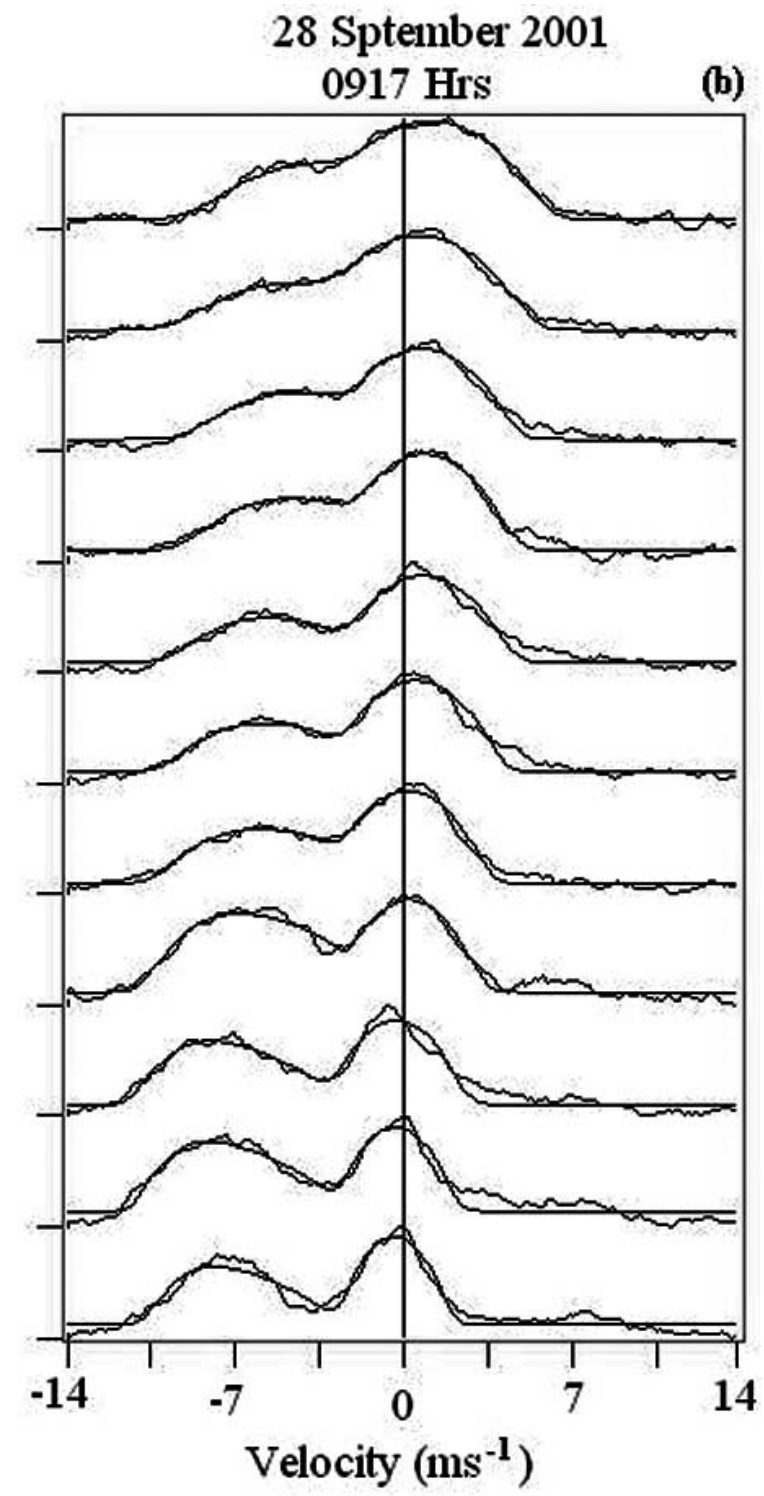

Fig. (7). Height normalized profile of power spectrum observed (fluctuating line) and fitted (smooth line) during (a) stratiform precipitation on 26 September 2001 and (b) convective precipitation on 28 September 2001. 
27 September 2001 (0300 - 0359 LT)

$\mathrm{Ze}(\mathrm{dB})$

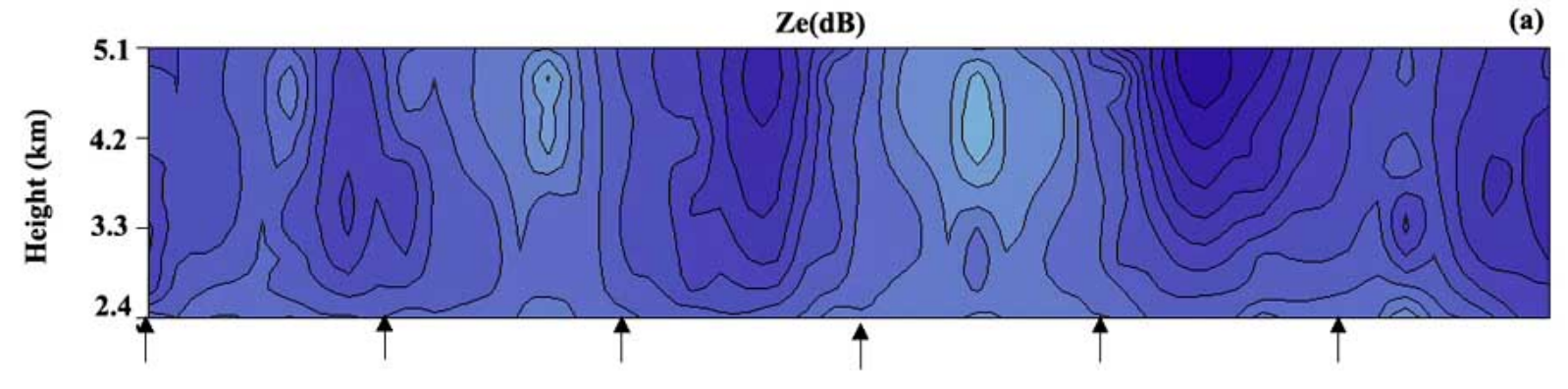

Rain rate (mm/Hr)

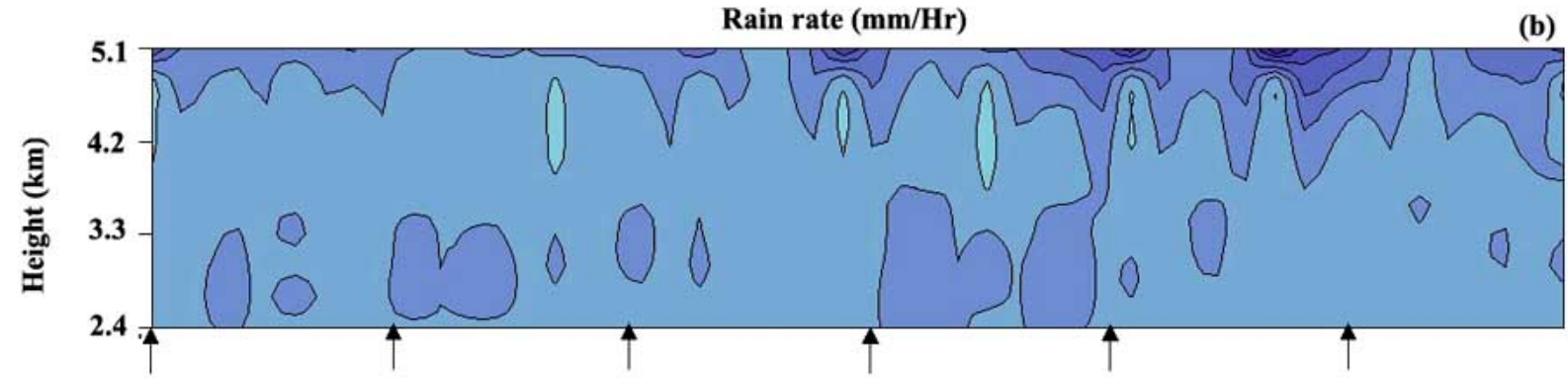

(b)

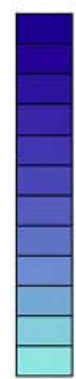

1.8

1.4

1.0

0.6

0.2

$N(t)$

(c)
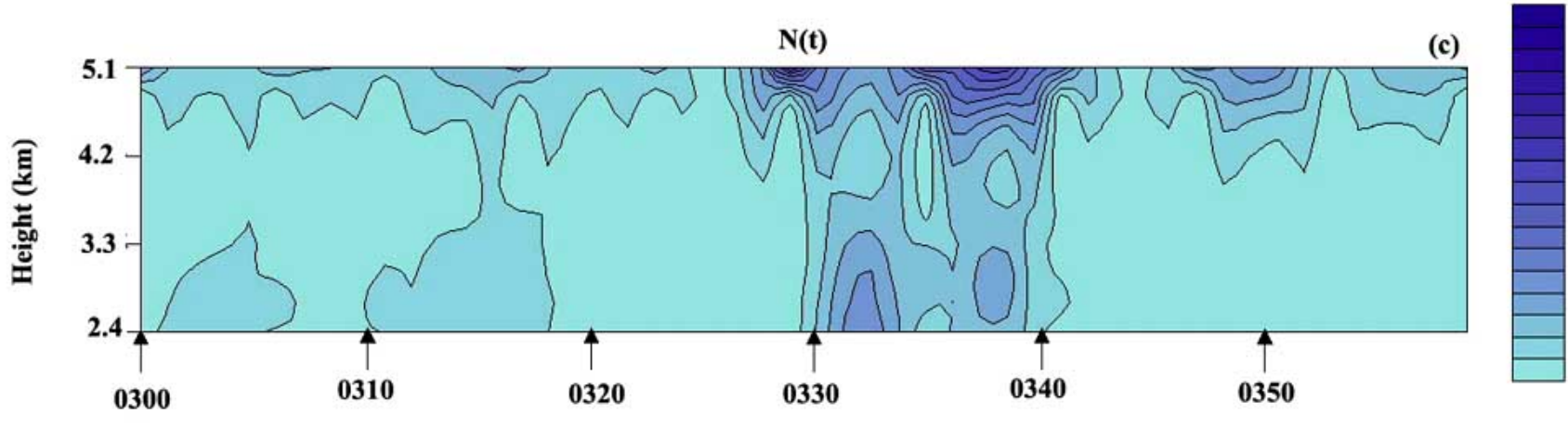

3200

2800

2400

2000

1600

1200

800

400

Time (LT)

Fig. (8). Time-height contours of rainfall bulk parameters and drop concentration, as retrieved by the radar on 27 September 2001 , during $0300-0400$ LT.

clearly see the smaller reflectivity values between $03: 30$ and 03:40 LT with $Z_{\mathrm{e}}$ reaching as low as $20 \mathrm{~dB}$. Corresponding rain rate and drop concentrations show a relative maximum during this period. It indicates the lack of bigger drops and dominance of smaller drops, during this period. The smaller drops produce weak reflectivities because of the strong dependency of reflectivity on drop diameter. However, more number of smaller drops provides larger rain rates, as seen in the case study.

The statistics of DSD retrieved for all rain events during the typhoon passage period are tabulated in Table 1. These statistics are compared with rain gauge recorded rain rates for providing credibility to the retrieval technique and also to our results. Table shows the maximum value of rain rate estimated, column integrated mean value and its standard deviation along with the range of reflectivity and DSD. Rain gauge recorded rain rate $(50 \mathrm{~m}$ away from radar site), its mean value and standard deviation are also included in the table for comparison. In the case of stratiform precipitation, most of the time rain gauge recorded values seem to be lower than the radar estimates. On the other hand, the radar estimates of rain rate seem to be lower than the rain gauge measurements in the convection. This indicates that the processes like evaporation in stratiform rain and collision and coalescence in convection are occurring predominantly during the event described above.

\section{SUMMARY}

A detailed analysis is carried out on VHF radar observations during the passage of Lekima typhoon to characterize the echoes due to clear air and precipitation and also microphysical changes associated with it. During the passage of typhoon Lekima, the convection, mostly weak in nature, is embedded in predominantly stratiform precipitation. There are two moderate convective cells and one shallow convective cell was observed in three-day observation, all these cells have a duration of about 15 minutes. This may be a characteristic feature of the convective phenomena within the cells of the rain-bands that move with the typhoon. The clear air and precipitation echoes were separated wherever possible and compared their 
Table 1. Precipitation Parameters Obtained from Radar Measurements During the Passage of the Typhoon and Corresponding Rain Gauge Measured Rain Rate Values

\begin{tabular}{|c|c|c|c|c|c|c|c|c|}
\hline \multirow{2}{*}{ Date and Time } & \multirow{2}{*}{$\begin{array}{c}\mathrm{Ze} \\
(\mathrm{dB})\end{array}$} & \multicolumn{6}{|c|}{ Rain Rate $(\mathrm{mm} / \mathrm{hr})$} & \multirow{2}{*}{$\begin{array}{c}\text { DSD Range } \\
\mathbf{N}(\mathrm{t})\left(\mathrm{mm}^{6} \mathrm{~m}^{-3}\right)\end{array}$} \\
\hline & & Max & Mean & STD & Max & Mean & STD & \\
\hline $\begin{array}{l}\text { 26 September } \\
0925-1000 \text { LT }\end{array}$ & $27-39$ & 5.91 & 2.44 & 1.22 & 6.5 & 0.94 & 1.2 & $\begin{array}{c}8-5474 \\
\text { (Stratiform) }\end{array}$ \\
\hline $\begin{array}{l}27 \text { September } \\
0200-0300 \text { LT }\end{array}$ & $16-29$ & 1.05 & 0.36 & 0.19 & 0.5 & .220 & 0.10 & $\begin{array}{c}3-3163 \\
\text { (Stratiform) }\end{array}$ \\
\hline $\begin{array}{l}27 \text { September } \\
0300-0400 \text { LT }\end{array}$ & $18-31$ & 1.73 & 0.36 & 0.24 & 0.7 & 0.36 & 0.15 & $\begin{array}{c}3-3156 \\
\text { (Stratiform) }\end{array}$ \\
\hline $\begin{array}{l}27 \text { September } \\
0400-0500 \mathrm{hrs}\end{array}$ & $16-27$ & 1.05 & 0.308 & 0.19 & 0.5 & 0.36 & 0.12 & $\begin{array}{c}5-2015 \\
\text { (Stratiform) }\end{array}$ \\
\hline $\begin{array}{l}27 \text { September } \\
0500-0545 \text { LT }\end{array}$ & $15-28$ & 1.31 & 0.38 & 0.28 & 0.5 & 0.24 & 0.08 & $\begin{array}{c}9-3780 \\
\text { (Stratiform) }\end{array}$ \\
\hline $\begin{array}{l}28 \text { September } \\
0906-0920 \mathrm{Hrs}\end{array}$ & $26-42$ & 6.67 & 3.01 & 1.23 & 7.1 & 3.52 & 2.09 & $\begin{array}{c}84-5998 \\
\text { (Convective) }\end{array}$ \\
\hline $\begin{array}{l}28 \text { September } \\
1509-1625 \text { LT }\end{array}$ & $23-33$ & 2.8 & 1.22 & 0.66 & 0.8 & 0.46 & 0.21 & $\begin{array}{c}13-3447 \\
\text { (Stratiform) }\end{array}$ \\
\hline
\end{tabular}

moments as a function of height and precipitating system. The results are found to be largely consistent with the results obtained at other regions during the passage of MCS. During the observational period, in other words during typhoon passage days, the height of the $0^{\circ} \mathrm{C}$ isotherm level is observed at a slightly higher altitude than that of a normal day. It needs further investigation to understand the reasons for such a behavior.

The rain DSD has been derived and the rainfall bulk parameters are used to understand the microphysical processes occurring in different stages of Typhoon. Further, the rainfall retrieved from radar measurements is compared with that obtained from surface rain gauge. The comparisons reveal interesting features. During stratiform precipitation, rain gauge recorded rainfall values are often lower than the values estimated by the radar. Contrastingly, the surface rainfall rates are more than the radar derived values in convection. Evaporation and collision and coalescence seem to be playing a major role in the evolution of drops. These observations suggest that the microphysical processes are quite different in different precipitating systems (stratiform and convective precipitation).

\section{REFERENCES}

[1] Balsley BB, Gage KS. The MST radar technique: Potential for atmospheric studies. Pure Appl Geophys 1980; 118: 452-93.

[2] Larsen MF, Röttger J. VHF and UHF Doppler radars as tools for synoptic research. Bull Am Meteor Soc 1982; 63: 996-1008.

[3] Battan LJ. Radar observations of the atmosphere. Chicago: University of Chicago Press 1973; p. 85.

[4] Lucas C, MacKinnon AD, Vincent RA, May PT. Raindrop size distribution retrievals from a VHF boundary layer profiler. J Atmos Oceanic Technol 2004; 21: 45-60.
McDonald AJ, Carey-Smith TK, Hooper DA, Fraser GJ, Lublow BP. The effect of precipitation on the wind-profiler clear air returns. Ann Geophys 2004; 22: 3959-70.

[6] Rajopadhyaya DK, May PT, Vincent RA. A general approach to the retrieval of raindrop size distributions from VHF wind profiler doppler spectra: modeling results. J Atmos Oceanic Technol 1993; 10: 710-7.

[7] Rao TN, Rao DN, Raghavan S. Tropical precipitating system observed with Indian MST Radar. Radio Sci 1999; 34: 1125-39.

[8] Campos EF, Fabry F, Hocking W. Precipitation measurements using VHF wind profiler radars. Measuring rainfall and vertical air velocities using only observations with a VHF radar. Radio Sci 2007; 42: RS3003

[9] Chu YH, Lee-Po C. The investigation of the atmospheric precipitations by using Chung-Li VHF radar. Radio 1991; 26: 71729.

[10] Fukao S, Wakasugi K, Sato T, et al. Direct measurement of air and precipitation particle motion by very high frequency Doppler radar. Nature 1985; 316: 712-4.

[11] Ralph FM. Using radar measured radial vertical velocities to distinguish precipitation scattering from clear air scattering. J Atmos Oceanic Technol 1995; 12: 257-67.

[12] Rao TN, Rao DN, Mohan K, Raghavan S. Classification of tropical precipitating systems and associated Z-R relationships. J Geophys Res 2001; 106; 17: 699- 711.

[13] Reddy KK, Peng SS, Chu YS. Study of a precipitating cloud system using Chung-Li VHF radar. Radio Sci 2002; 37: 20-1.

[14] Sato T, Doji H, Iwai H, et al. Computer processing for deriving drop-size distribution and vertical air velocities from VHF Doppler radar spectra. Radio Sci 1990; 25: 961-73.

[15] Wakasugi K, Mizutani A, Matsuo M, Fukao S, Kato S. A direct method for deriving drop size distribution and vertical air velocities from VHF Doppler radar spectra. J Atmos Oceanic Technol 1986; 3: 623-9.

[16] Wakasugi K, Mizutani A, Matsuo M, Fukao S, Kato S. Further discussion deriving drop-size distribution and vertical air velocities directly from VHF Doppler radar spectra. J Atmos Oceanic Technol 198; 4: 170-9.

[17] Sato K. Small-scale wind disturbances observed by the MU radar during the passage of typhoon Kelly. J Atmos Sci 1993; 50: 51837. 
[18] Sato T, Ao N, Yamamoto M, Fukao S, Tsuda T, Kato S. A typhoon observed with the MU radar. Mon Weather Rev 1991; 755-68.

[19] Teshiba M, Hashiguchi H, Fukao S, Shibagaki Y. Typhoon 9707 observations with the MU radar and L-band boundary layer radar. Ann Geophys 2001; 19: 925-31.

[20] Marshal JS, Palmer WM. The distribution of rain drops with sizes. J Meteorol 1948; 5: 165-6.

[21] Reddy KK, Nakamura K, Kozu T, Jain AR, Rao DN. Tropical precipitation studies using $\mathrm{VHF} / \mathrm{L}$ band wind profilers and disdrometer over Gadanki, India. Proc SPIE 2000; 4152: 62-72.

[22] Röttger J, Liu CH, Chao JK, et al. The Chung-Li VHF radar: Technical layout and a summary of initial results. Radio Sci 1990; 25: 487-502.

[23] Hildebrand PH, Sekhon RS. Objective determination of the noise level in Doppler spectra. J Appl Meteorol 1974; 13: 808-11.

[24] Woodman RF. Spectral moments estimation in MST radars. Radio Sci 1985 ; 20: 1185-95.

[25] Houze RA. Cloud dynamics. San Diego, California: Academic Press Inc 1993; p. 197.
Atlas D, Ulbrich CW, Marks Jr FD, et al. Partitioning tropical oceanic convective and stratiform rains by draft strength. J Geophys Res 2000; 105: 2259-67.

[27] Chu YH, Song JS. Observations of precipitation associated with a cold front using a VHF wind profiler and a ground-based optical rain gauge. J Geophys Res 1998; 11: 11401-409.

[28] Sato T, Woodman RF. Spectral parameter estimation of CAT radar echoes in the presence of fading clutter. Radio Sci 1982; 4: 817-26.

[29] Ulbrich CW. Natural variations in the analytical form of the raindrop size distribution. J Climate Appl Meteorol 1983; 22: 176475.

[30] Cerro C, Codina B, Bech J, Lorente J. Modeling raindrop size distribution and $\mathrm{Z}(\mathrm{R})$ relations in the western Mediterranean area. J Appl Meteorol 1997; 36: 1470-9.

[31] Gossard EE. Measuring drop-size distributions in clouds with a clear-air-sensing Doppler radar. J. Atmos Oceanic Technol 1988; 5: 640-9.

[32] Gunn R, Kinzer GD. The terminal velocity of fall for water droplets in stagnant air. J Meteorol 1949; 6: 243-8.

(C) Anandan et al.; Licensee Bentham Open.

This is an open access article licensed under the terms of the Creative Commons Attribution Non-Commercial License (http://creativecommons.org/licenses/by$\mathrm{nc} / 3.0 /$ ) which permits unrestricted, non-commercial use, distribution and reproduction in any medium, provided the work is properly cited. 